\title{
Knowing Behavior Matters Doesn't Hurt: The Effect of Individual Climate Behavior Messaging on Green Policy Support
}

\author{
Abdurakhim Rakhimov* and Erik Thulin \\ Center for Behavior \&o the Environment, Rare
}

\begin{abstract}
:
Individual behavior change offers a large potential to curb greenhouse gas emissions. However, messaging promoting individual behavior change has been criticized as a strategy for addressing climate change due to its potential to diminish climate policy support. In a pre-registered study with a representative sample of American adults $(n=1069)$, we found that messages recommending the adoption of high-impact individual climate behaviors, such as flying less, and highlighting their large impact do not affect support for a carbon tax. In an exploratory analysis, we found that this messaging results in a higher intention to adopt several climate behaviors. We recommend that policies that advocate for individual climate action be best understood as complements, rather than undermining substitutes, to broad carbon regulatory policy.
\end{abstract}

*Corresponding author: rrakhimov@rare.org

Version 2/24/2022 
The Earth is facing adverse and unprecedented risks from human-caused climate change, which are predicted to disproportionately harm the world's most disadvantaged communities $[1,2]$. Thankfully, many solutions to mitigate climate change already exist [3, 4]. Yet, after technological improvements, increasing affordability of these solutions, and decades of consensus on the threat of rising emissions, there is still a lack of meaningful progress toward a carbon-neutral future. The IPCC's Special Report on Global Warming of $1.5^{\circ} \mathrm{C}$ (SR15) suggests that programs that encourage individuals to adopt behaviors that reduce their carbon footprint present a clear complement to proposed policy solutions [5]. In fact, over half of the solutions designed to address climate change require societal and behavioral changes [6]. The rising popularity of behavioral solutions presents policymakers and program designers with new strategies that they can use to complement traditional climate legislation [7]. These solutions could inform the design of policy interventions that change what we eat, how we travel, what energy we use, and what we do with waste, all of which have been shown to have a high impact on carbon emissions when scaled up to the population level [8].

Individual behavior change, however, received skepticism from academics, climate scientists, and the general public due to its potential to diminish climate policy support [9-11]. These critics argue that climate change has deep systemic causes that cannot be sufficiently addressed by individual decisions, and that prominently discussing individual behavior change can make it appear as a substitute for regulatory policy change, therefore undermining support for larger systemic policy efforts.

In the context of climate emergency, it is crucial for policymakers and program designers to know which strategies in their toolkit should be deployed to combat climate change. This includes understanding whether programs that rely on messaging to promote high-impact individual behavior change risk undermining policy support. The existing literature assessing such effects is mixed and largely indirect. Recent work has argued that messages recommending individual behaviors reduce willingness to support political candidates with a pro-climate agenda [9]. Similarly, messages that primed people of their past pro-environmental behaviors (PEBs) and included recommended individual actions to reduce energy consumption were found to reduce support for climate change policy [12]. Research in the related domain of policymaker decision-making found that policy support for a carbon tax is undermined when policymakers consider less intrusive "nudge" based policies to encourage individual behavior change [13]. However, studies investigating the effect of inducting individuals to adopt pro-environmental behaviors have shown no effect on climate policy support [14-16]. Indeed, a meta-analysis of increasing the adoption of pro-environmental individual behavior on climate policy support reveals no aggregate effect [17].

To inform whether policymakers and program designers should include behavioral solutions which highlight the impact of individual action, we posed the following research question: Do messages that recommend the adoption of individual behaviors to address climate change affect individuals' 
support for a carbon tax? As a secondary investigation, we also aimed to assess whether the messages affect intention to adopt these behaviors.

\section{Methods}

\section{Participants}

We collected responses from 1,085 U.S. participants via the Prolific.co platform. The sample was stratified by age, sex, and ethnicity, based on quotas designed to be representative of the U.S. Census adults. Past research with respondents from similar platforms has found that resulting demographic and empirical findings track well with U.S. national probability sample benchmarks [18]. Per our preregistration, we excluded 16 respondents from analyses due to incomplete survey responses. Our final sample size was 1,069. The mean age was 45 years and $50 \%$ of participants were female. Before beginning, all participants provided consent to participate. For study materials, including the consent form and pre-registration, see OSF (https://osf.io/m9ah3/).

\section{Procedure}

We randomly assigned participants to either the individual behavior messaging condition or a neutral control. To ensure that the impact of individual behavior on climate was not confounded with the saliency of the consequences of climate change, all participants were first shown a paragraph describing the Intergovernmental Panel on Climate Change (IPCC) finding that global temperatures are likely to rise in the future [1]. In the experimental condition, we presented participants with a message describing seven high-impact individual climate-mitigating behaviors which previous research has highlighted as highly impactful to adopt [8] - reduce the amount of meat in your diet, switch to a green energy provider, install solar panels, reduce food waste in your home, make an electric vehicle $(\mathrm{EV})$ your next car purchase, reduce the amount you fly by at least one flight a year, and purchase carbon offsets to offset your annual emissions - that Americans could adopt to reduce their carbon emissions. To highlight the impact of these behaviors we informed participants that if each behavior was adopted by $10 \%$ of Americans, the U.S. would be back on track to meet its global commitments to reduce carbon emissions [8]. Participants in the control condition were not shown the messaging describing the seven behaviors or their large potential to address climate change.

Next, all participants stated their support for a carbon tax ("Impose a carbon tax on companies and products based on how much emissions they create", adapted from [13]). Their response (1 = Yes or $0=N o$ ) formed our first dependent variable. To reduce possible demand effects [19], the carbon tax policy question was embedded in a matrix with a set of eight other questions focused on other government policies unrelated to climate (for example, "Introduce government-mandated paid maternity leave").

For six of the seven behaviors, we asked participants "If you had to guess, what is the percent chance you will take each of the actions in the next 12 months?". Due to the infrequency of 
purchasing a vehicle in the United States, intention to purchase an electric vehicle was measured through the following item: "If you had to guess, what is the percent chance you will make an electric vehicle (EV) your next car purchase?”. Participants responded to all behavioral intention measures on a 100 pt slider scale $(0=$ No chance at all to $100=$ Certain $)$. To create a single behavioral intention index variable representing a respondent's overall propensity to take individual action, we standardized each behavioral intention variable (subtracted the mean, divided by the standard deviation) and then took the average of all seven values for every respondent. This individual-level index formed our second dependent variable.

We also collected several demographic measures, such as gender, age, ethnicity, education, political viewpoint, and household income.

\section{Analytic strategy}

To evaluate whether our messaging affected policy support and whether the difference between conditions was equivalent, we conducted a combination of pre-registered traditional null hypothesis significance tests (NHST) and equivalence tests. To test for this equivalence, we relied on two onesided tests (TOST) procedure that allows us to specify a lower $\left(\Delta_{\mathrm{L}}\right)$ and upper bound $\left(\Delta_{\mathrm{U}}\right)$ based on the smallest effect size of interest. The results falling within the bounds are deemed equivalent to the absence of a meaningful effect [20].

In the TOST procedure, the null hypothesis is the presence of a true effect of $\Delta_{\mathrm{L}}$ or $\Delta_{\mathrm{U}}$. The alternative hypothesis is that the effect is smaller than the smallest effect size of interest and it falls within the equivalence bounds. The observed effect is compared against $\Delta_{\mathrm{L}}$ and $\Delta_{\mathrm{U}}$ in two one-sided tests, one testing if the effect is larger than the lower bound of the equivalence range, and one testing whether the effect is smaller than the upper bound of the equivalence range. When both these one-sided tests can be statistically rejected, we can conclude that the observed effect falls within the equivalence bounds and is close enough to zero to be practically equivalent. Previous research found that messaging on the effect of nudge policy reduced policy support for a carbon tax by $18 \%$ [13]. Based on this finding, we established the smallest effect size of interest of $10 \%$ change in carbon tax support both for traditional NHST of difference as well as the TOST of equivalence.

To test our secondary hypothesis of whether exposure to messaging affects individuals' intention to adopt high-impact climate behaviors, we followed the same pre-registered analytical procedure of testing for both difference and equivalence, evaluating whether the differences in the mean reported intention to adopt behaviors were statistically equivalent. Based on literature standards for a small effect [21], we set $d=0.2$ as our smallest effect size of interest. Therefore, the equivalence range goes from $\mathrm{d}=-0.2$ to $\mathrm{d}=0.2$. 


\section{Results}

Figure 1. Exposure to the message emphasizing the large climate-mitigating impact of individual behaviors does not affect support for the carbon tax

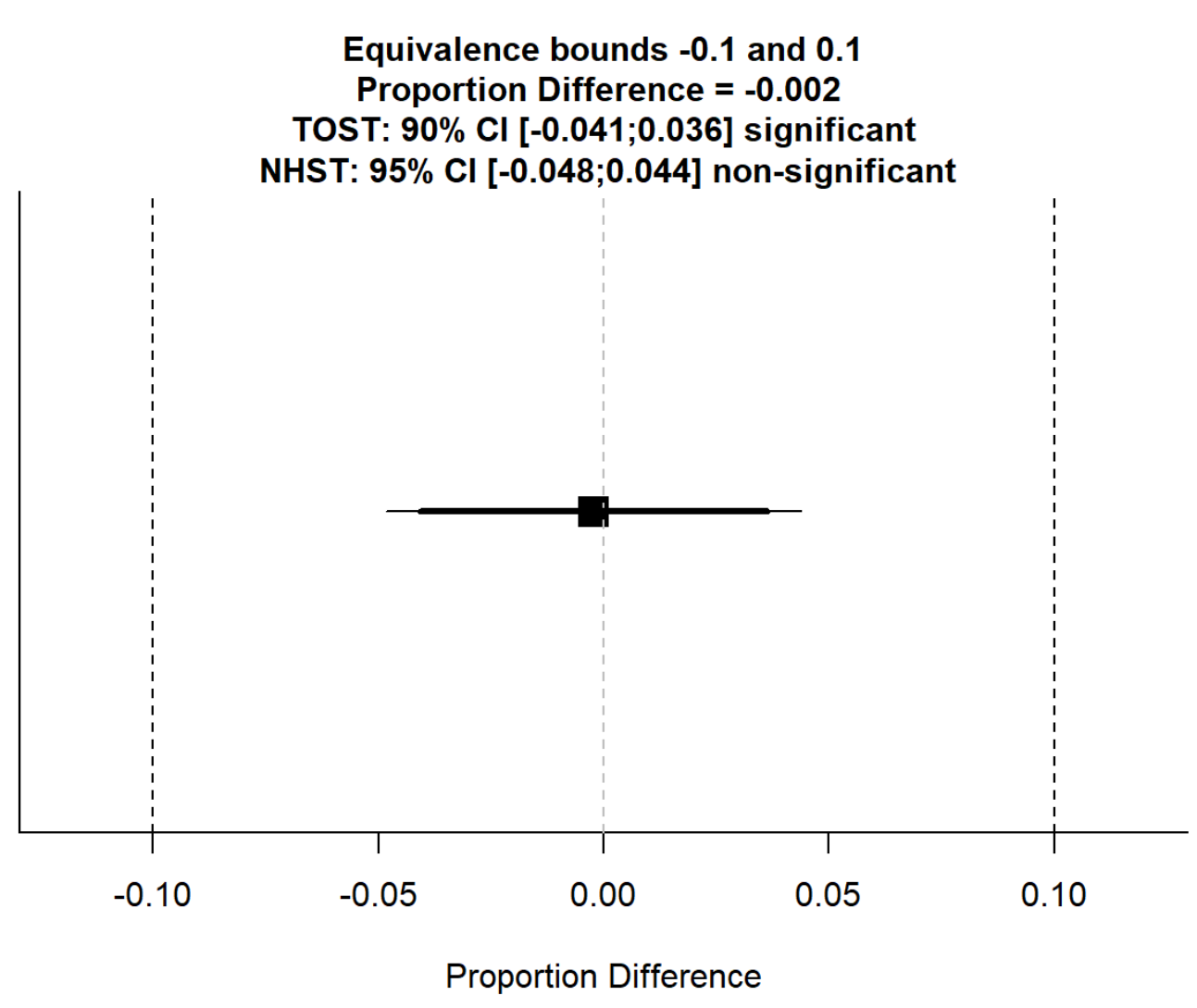

Proportion difference, $\mathrm{p}=-0.002$, (black square) plotted with $90 \%$ TOST confidence intervals (thick horizontal lines) and 95\% NHST confidence intervals (thin horizontal lines) with equivalence bounds $\Delta_{\mathrm{L}}=-0.1$ and $\Delta_{\mathrm{U}}=0.1$ for a test result that is statistically equivalent and not statistically different from zero. A 90\% TOST confidence interval (CI; $1-2 \alpha)$ is used instead of a $95 \%$ CI $(1-\alpha)$ because two one-sided tests (each with an $\alpha$ of $5 \%$ ) are performed.

Following the analytic procedure of testing for both difference and equivalence, we find no evidence that messaging on the importance of individual action reduces support for a carbon tax. Specifically, those in the individual behavior condition supported a carbon tax $0.2 \%$ less than those in the control condition, which is statistically equivalent $(z=4.169, \mathrm{p}<0.001)$ and not statically different $(z=-0.0938, p=0.925)$ from zero.

To test our secondary hypothesis of whether messaging affects individuals' intention to adopt highimpact climate behaviors, we followed the same analytic procedure of testing for both difference 
and equivalence. We find the differences in the mean intention to adopt behaviors $(\mathrm{d}=0.124)$, while small, are statistically distinguishable from zero $(\mathrm{t}(1058.87)=2.02, \mathrm{p}=0.043)$ and not statistically equivalent $(\mathrm{t}(1058.87)=-1.24, \mathrm{p}=0.107)$. That is, the messaging statistically significantly increased average intention to adopt the targeted high-impact climate behaviors. To evaluate the degree to which the messaging affected intention to adopt each behavior highlighted in the messaging, we conducted an exploratory analysis of the effect of the messaging on each behavior (Figure 2).

Figure 2. Exposure to the message positively affects the reported intention to adopt several high-impact individual behaviors

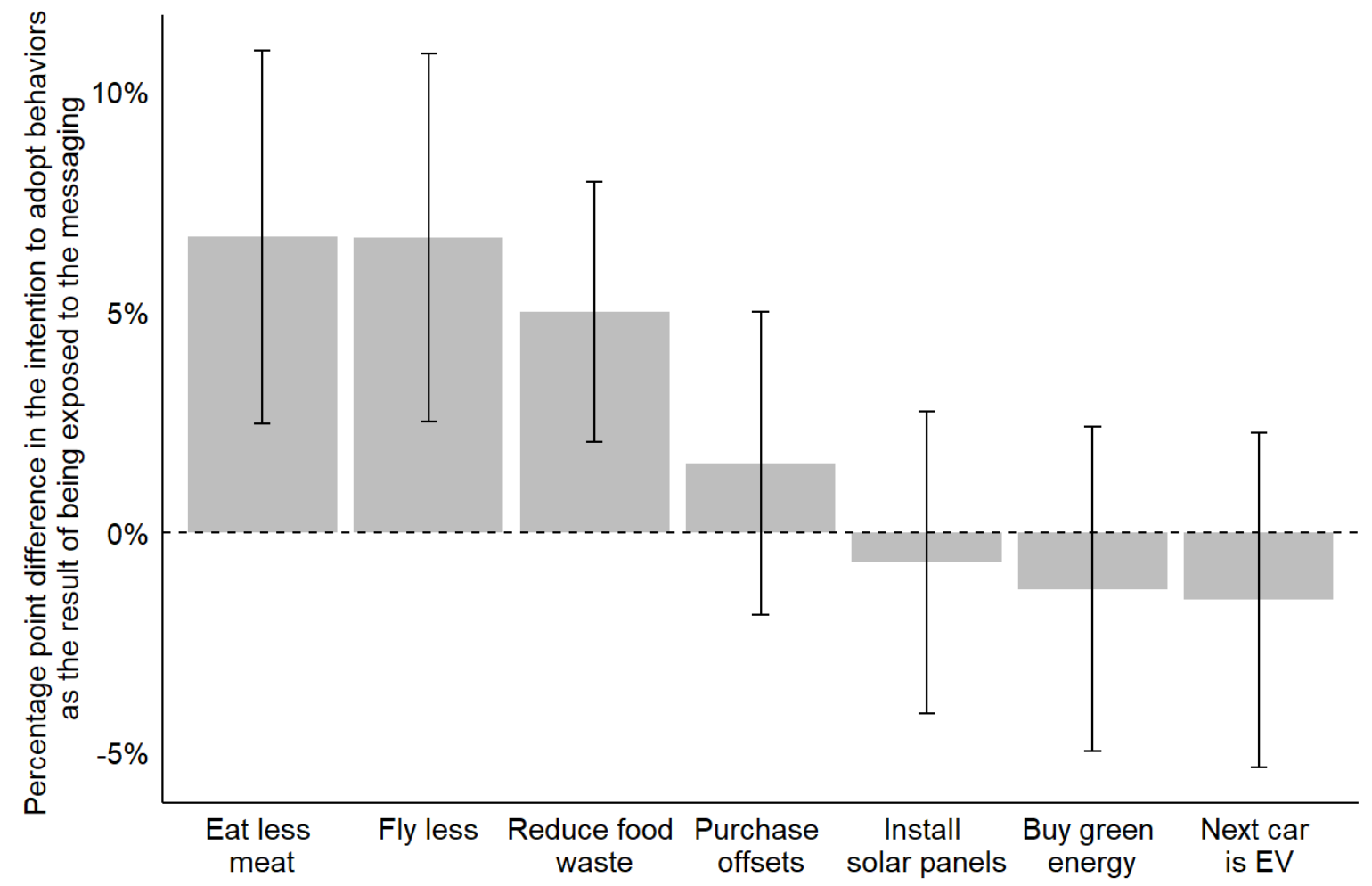

Percentage point difference in the intention to adopt seven high-impact climate behaviors as the result of being exposed to the messaging. Error bars represent 95\% confidence intervals.

We found that those exposed to the messaging on the impact of adopting individual behaviors reported statistically significantly higher intention to eat less meat, fly less, and reduce food waste. We found no statistically significant effect of messaging on the intention to adopt the remaining four behaviors. We hypothesize that this may be due to the three behaviors which show a significant change all lacking a monetary cost and therefore being perceived as easier to adopt, whereas those that showed non-significant effects all have monetary costs. 


\section{Discussion \& Implications for Policy}

Previous discourse has expressed concern that supporting individual actions for the environment can diminish support for climate policy. As a result, programs that recommend individual behavior change have been discouraged in favor of regulatory policy [9-11]. However, despite growing public concern about climate change in the United States [22], policies that aim at lowering greenhouse gas emissions and helping to mitigate climate change, such as a carbon tax, face political gridlock. In part due to these political challenges, these much-needed regulatory policies can be difficult to implement in the near term. Complementary to regulatory initiatives, behavioral policy solutions to climate change offer high mitigation potential as well as the opportunity to create demand for greater technological and regulatory shifts while being more politically palatable in the near term. In addition, behavioral solutions can offer positive impacts on a range of challenges at lower costs than those associated with traditional economic policies [23]. For example, the Department of Energy supported Solarize campaigns apply social influences to drive the adoption of household solar with a direct program cost of $\$ 21$ per ton of CO2 reduced [24], a cost below the social cost of emissions [25]. However, due to the critical need for comprehensive policy reform, policies encouraging individual action may not be worth pursuing if they undermine broader support for regulatory approaches like a carbon tax.

We find that messaging recommending individual action on climate change does not undermine policy support while increasing the intention to adopt several high-impact behaviors. Based on our results, policymakers working to address climate change should not view regulatory policy and policies supporting behavior change as an "either-or" choice. Policymakers are therefore encouraged to view behavioral solutions as an important complement, rather than undermining substitute, to their traditional climate policy work, and to instead rely on the entire suite of climate mitigation tools available to them. 


\section{References}

1. IPCC (2018): Summary for Policymakers. In: Global Warming of $1.5^{\circ} \mathrm{C}$. An IPCC Special Report on the impacts of global warming of $1.5^{\circ} \mathrm{C}$ above pre-industrial levels and related global greenhouse gas emission pathways, in the context of strengthening the global response to the threat of climate change, sustainable development, and efforts to eradicate poverty. World Meteorological Organization, Geneva, Switzerland.

2. GCA (2019). Adapt Now: A Global Call for Leadership on Climate Resilience. Global Center on Adaptation, World Resources Institute, Rotterdam.

3. Hawken, P. (2017). Drawdown: The most comprehensive plan ever proposed to reverse global warming. New York: Penguin Books.

4. Foley, J., Wilkinson, K., Frischmann, C., Allard, R., Gouveia, J., Bayuk, K., Mehra, M., Toensmeier, E., Forest, C., Daya, T., Gentry, D., Myhre, S., Mukkavilli, s. K., Yussuff, A., Mangotra, A., Metz, P., Wartenberg, A., Anand, C., Jafary, M., \& Rodriguez, B. (2020). The Drawdown Review (2020)—Climate Solutions for a New Decade.

https://doi.org/10.13140/RG.2.2.31794.76487

5. de Coninck, H., Revi, A., Babiker, M., Bertoldi, P., Buckeridge, M., Cartwright, A., Dong, W., Ford, J., Fuss, S., Hourcade, J.-C., Ley, D., Mechler, R., Newman, P., Revokatova, A., Schultz, S., Steg, L., Sugiyama, T., 2018. Strengthening and implementing the global response, in: Masson-Delmotte, V., Pörtner, H.-O., Roberts, D., Skea, J., Shukla, P.R., Pirani, A., Moufouma-Okia, W., Péan, C., Pidcock, R., Connors, S., Matthews, J.B.R., Chen, Y., Zhou, X., Gomis, M.I., Lonnoy, E., Maycock, Tignor, M., Waterfield, T. (2018). Global Warming of $1.5^{\circ} \mathrm{C}$. An IPCC Special Report on the Impacts of Global Warming of $1.5^{\circ} \mathrm{C}$ above Pre-Industrial Levels and Related Global Greenhouse Gas Emission Pathways, in the Context of Strengthening the Global Response to the Threat of Climate Change, Sustainable Development, and Efforts to Eradicate Poverty. World Meteorological Organization, Geneva, Switzerland.

6. Committee on Climate Change, (2020). The Sixth Carbon Budget. The UK's path to Net Zero.

7. Dietz, T., Gardner, G. T., Gilligan, J., Stern, P. C., \& Vandenbergh, M. P. (2009). Household actions can provide a behavioral wedge to rapidly reduce US carbon emissions. Proceedings of the National Academy of Sciences, 106(44), 18452-18456.

8. Heller, K., Berger, M., Gagern, A., Rakhimov, A., Thomas, J., Thulin, E. (in press). Six Focus Behaviors for Policymakers Mitigate Climate Change. Behavioral Science and Policy Association. https://doi.org/10.31234/osf.io/y4we7

9. Palm, R., Bolsen, T., \& Kingsland, J. T. (2020). “Don't Tell Me What to Do”: Resistance to Climate Change Messages Suggesting Behavior Changes. Weather, Climate, and Society, 12(4), 827-835. https://doi.org/10.1175/WCAS-D-19-0141.1

10. Goldstein, J.S. and Qvist, S. A. (2019). A Bright Future: How Some Countries Have Solved Climate Change and the Rest Can Follow. New York: Public Affairs. 
11. Mann, M. E. (2019). Lifestyle Changes Aren't Enough to Save the Planet. Here's What Could. Time. https://time.com/5669071/lifestyle-changes-climate-change/

12. Werfel, S. H. (2017). Household behaviour crowds out support for climate change policy when sufficient progress is perceived. Nature Climate Change, 7(7), 512-515. https://doi.org/10.1038/nclimate3316

13. Hagmann, D., Ho, E. H., \& Loewenstein, G. (2019). Nudging out support for a carbon tax. Nature Climate Change, 9(6), 484-489. https://doi.org/10.1038/s41558-019-0474-0

14. Lacasse, K. (2016). Don't be satisfied, identify! Strengthening positive spillover by connecting pro-environmental behaviors to an "environmentalist" label. Journal of Environmental Psychology, 48, 149-158. https://doi.org/10.1016/j.jenvp.2016.09.006

15. Truelove, H. B., Yeung, K. L., Carrico, A. R., Gillis, A. J., \& Raimi, K. T. (2016). From plastic bottle recycling to policy support: An experimental test of pro-environmental spillover. Journal of Environmental Psychology, 46, 55-66. https://doi.org/10.1016/j.jenvp.2016.03.004

16. Truelove, H. B., \& Nugent, M. R. (2020). Straw wars: Pro-environmental spillover following a guilt appeal. Journal of Environmental Psychology, 72, 101521. https://doi.org/10.1016/j.jenvp.2020.101521

17. Maki, A., Carrico, A. R., Raimi, K. T., Truelove, H. B., Araujo, B., \& Yeung, K. L. (2019). Meta-analysis of pro-environmental behaviour spillover. Nature Sustainability, 2(4), 307-315. https://doi.org/10.1038/s41893-019-0263-9

18. Coppock, A., \& McClellan, O. A. (2019). Validating the demographic, political, psychological, and experimental results obtained from a new source of online survey respondents. Research \& Politics. https://doi.org/10.1177/2053168018822174

19. Zizzo, D. J. (2010). Experimenter demand effects in economic experiments. Experimental Economics, 13, 75-98. https://doi.org/10.1007/s10683-009-9230-z

20. Lakens, D., Scheel, A. M., \& Isager, P. M. (2018). Equivalence Testing for Psychological Research: A Tutorial. Advances in Methods and Practices in Psychological Science, 1(2), 259-269. https://doi.org/10.1177/2515245918770963

21. Cohen, J. (1988). Statistical Power Analysis for the Behavioral Sciences. Lawrence Erlbaum Associates.

22. Leiserowitz, A. Maibach, E., Rosenthal, S., Kotcher, J., Neyens, L., Marlon, J., Carman, J., Lacroix, K., \& Goldberg, M. (2022). Global Warming's Six Americas, September 2021. Yale University and George Mason University. New Haven, CT: Yale Program on Climate Change Communication.

23. Allcott, H., Rogers, T. (2014). The Short-Run and Long-Run Effects of Behavioral Interventions: Experimental Evidence from Energy Conservation. American Economic Review 104, 3003-3037. https://doi.org/10.1257/aer.104.10.3003

24. Gillingham, K., Bollinger, B. (2019). Social Learning and Solar Photovoltaic Adoption. SSRN Scholarly Paper No. ID 3500930. Social Science Research Network, Rochester, NY. https://doi.org/10.2139/ssrn.3500930 
25. EDF (2020). The true cost of carbon pollution [WWW Document]. Environmental Defense Fund. Retrieved from https://www.edf.org/true-cost-carbon-pollution 